\title{
A Critical Review of Scales Used in Social Capital Research
}

\author{
Isyaku Salisu ${ }^{1)} \&$ Norashida Hashim ${ }^{2)}$ \\ ${ }^{1)}$ School of Business Management, College of Business Universiti Utara Malaysia (UUM) 06010 Sintok, Kedah \\ DarulAman, Malaysia. \\ ${ }^{2)}$ School of Business Management, College of Business Universiti Utara Malaysia (UUM) 06010 Sintok, Kedah \\ DarulAman, Malaysia.
}

\begin{abstract}
This paper reviewed some of the most commonly used scales of social capital researches. Depending on the context, among these scales, some of them were found to be used more frequently than others. This paper discusses some of these scales for future researches. These are, name generator, position generator, resource generator, Social capital assessment tool (SCAT), Adapted Social Capital Assessment Tool (A-SCAT), Personal Social Capital Scale. After critical assessment, Personal Social Capital Scale scales were found to be the best scales in assessing individual social capital as they possess best psychometric properties. Since Therefore, it is imperative for future study to use the best scales in measuring their research constructs. This paper suggests that there is the need for researchers to consider the current methodological strength of any given measurement from stream of literature before adapting or adopting. Doing so will certainly provide more meaningful result for inferences.
\end{abstract}

\section{Introduction}

It has been argued that, the more individual possesses social capital the greater the chance of achieving higher desired outcome (Chen et al., 2015). Consequently, a comprehensive review of studies on social capital revealed that the construct received considerable attention from both researchers and policy makers (Agénor\&Dinh, 2015; Barker, \& Thomson, 2015; Obikili, 2015; Park, Nunkoo, \& Yoon, 2015), cutting across majority of academic disciplines such as sociology, anthropology, economics, political science, management and entrepreneurship (Andrews, \& Brewer, 2015; Strzelecka, \& Wicks, 2015) in both developed and less developing economy (Roberts, \& Gannon, 2014). For its wider acceptability and applicability, van Deth, (2003) argued it "has become a minor industry in the social sciences" (p. 79). The concept is rooted in sociology (Unni, 2014; Kiani, 2012; Dehkordi, Hossieni, Naqipourfar, \&Torkamani, 2012) and was first studied by Durkheim in 1897 when examining how social influence relates to suicide (Durkheim, 1951), but Hanifan was the first to introduce the term social capital in academic arena (Ritchie \& Robison, 2012).

\section{Definitions of Social Capital}

There are a lot of contentions among scholars over what constitutes the term social capital, its wider applicability in almost all human endeavours (Lee, Park, \& Lee, 2015; Murayama et al., 2015; makes it more difficult to have a unified and widely acceptable definition, thus defining it has been a subject of debate among scholars (Bellamy, 2015; Lee et al., 2015; Kobayashi, Kawachi, Iwase, Suzuki, \& Takao, 2013). Yet, there is no satisfying consensus on how it should be defined (Agampodi, Agampodi, Glozier, \&Siribaddana, 2015). In attempt to define it, every field of study moulds it to suit its context (Villalonga-Olives\&Kawachi, 2015a, 2015b).

Although there are various definitions of the concept, Neves and Fonseca (2015), Woolcock (2010) argued that social capital is a polysemic construct having different but related definitions with one central idea "our social ties matter and bring us benefits" (Neves, \& Fonseca, 2015, p. 15) thus, "the manner in which networks and their emergent properties (e.g. trust and norms) can constitute a resource for their members" (Crossley, 2008, p. 477). Nevertheless, different scholars defined it for instance, as a tangible and intangible resources individuals and groups acquire through network relationship that aid in enhancing varied outcomes such as performance, success, and sustaining competitive advantage (Andrikopoulos, \&Economou, 2015; Bellamy, 2015; Lancee, 2015; Liang, Huang, Lu, \& Wang, 2015; Ou, Hsu, \& Ou, 2015; Villalonga-Olives, \&Kawachi, 2015a) For instance, Villalonga-Olives and Kawachi (2015b, p.47) defined social capital that capture both individual and group approaches as "the resources available to individuals and groups through membership in social networks". According to Ritchie and Robison (2012, p.16), "Social capital is a person's or group's sympathy for another person or group" Likewise, Chen, et al., (2015), Archuleta and Teasley (2013) and Chen, Stanton, Gong, Fang and Li, (2009) maintained that social capital is a part of the general network connections amassed by individuals in their lifetime that consist of four core features: reciprocity, resource-rich, trustworthiness and durability. From most of the definitions suggested by different scholars, one could easily 
deduced that most of them share four things in common; network, trust, norms and resource. Also, Ellison, Gray, Lampe, and Fiore, (2014) buttress that majority of these definitions share focus on illustrating the connections between social relationships and different outcomes. Hence (Ooi, Laing, \&Mair, 2014) defined it as social norms such as reciprocity, trust, network of relationship and resources accessed that enable teamwork and mutual action at both group and individual level. Furthermore, Chen et al., $(2009$, p. 306) argued "without network connections, there is no social capital".Also, Van Staveren and Knorringa, (2007, p. 107) buttress that the most comprehensive definition of the concept is "relations matter".

\section{Measuring Social Capital}

As contentious as the conceptualization and operationalization of the social capital, it is also difficult to measure (Agampodi et al., 2015; Hällsten, Edling, \&Rydgren, 2015; Villalonga-Olives, \&Kawachi, 2015a; Appel et al., 2014; Ritchie, \& Robison, 2012; Sabatini, 2009) and suffer methodological vagueness (Neves, 2013). Social science researchers are being criticized for absence of consensus on how social capital should be measured (Murphy, 2013; Ferri et al., 2009). Lack of appropriate measure that capture the construct deter from getting and understanding its clear nature, value and effect. Therefore, researchers need to weigh the pros and cons of each measure carefully before using, taking into cognisance the nature, context and objective of their study (Veerle et al., 2012). Furthermore, Lin and Erickson (2008) argued that, for social capital to be a tool for development, there is the need to have appropriate measure that will represent the true nature of it. But, multidimensionality and ever changing nature of the concept compound its measurement problem overtime as getting accurate and uniform measures (across all levels and contexts) is an impossibility.

To trigger social capital research, so many researchers validated scales for assessing social capital both at group and individual level (Veerle et al., 2012) most of which were emanated from developed countries (Agampodi, et al., 2015), scholars have debated extensively as to which measurement is the best. Although there is no consensus on one best measure, but some of them are preferred more than the others as they possess better psychometric properties. Some lists of the available measures are presented in table 1, but the most prominent and frequently used ones are hereby discussed.

\section{Table 1}

\begin{tabular}{|c|c|c|}
\hline 2 & Story, Taleb, Ahasan, \& Ali, 2015 & Short Version Of Adapted Social Capital Assessment Tool B - SASCAT-B \\
\hline 3 & Muskett, 2014 & WRSCIM \\
\hline 4 & Wang, Chen, Gong, \& Jacques-Tiura., 2014 & Personal Social Capital Scale 16 and Personal Social Capital Scale 8 \\
\hline 5 & Thuy\& Berry, 2013 & Australian Community Participation Questionnaire (ACPQ) \\
\hline 6 & Friche et al., 2013 & Neighborhood scale \\
\hline 7 & Carr, Cole, Ring, \&Blettner, 2011 & Internal Social Capital Among Family Business -ISC-FB \\
\hline 8 & $\begin{array}{l}\text { Borges, Campos, Vargas, Ferreira, \&Kawachi, } \\
2010\end{array}$ & Integrated Questionnaire on Social Capital -SCIQ \\
\hline 9 & Zimet, Dahlem, Zimet, \& Farley, 1988 & Multidimensional Scale of Perceived Social Support - MSPSS \\
\hline 10 & Moscardino et al., 2010 & Sense Of Community Index \\
\hline 11 & Modie-Moroka, 2009, Borges et al., 2010 & Perceived Social Capital Scale \\
\hline 12 & Looman\&Farrag, 2009 & Arabic Social Capital Scale \\
\hline 13 & Chen et al., 2009 & Personal Social Capital Scale - PCSC \\
\hline 14 & Mattoo et al., 2008 & Social Support Questionnaire \\
\hline 15 & $\begin{array}{l}\text { De Silva \&Harpham, 2007, De Silva et al. } \\
2006\end{array}$ & SASCAT \\
\hline 17 & Williams, 2006 & Internet Social Capital Scales - ISCS \\
\hline 18 & $\begin{array}{l}\text { Inclan, C., Hijar, M., Tovar, V., 2005; Krishna } \\
\text { \&Shrader } 2000\end{array}$ & Social Capital Assessment Tool - SCAT \\
\hline 19 & Harpham, Grant, \& Thomas, 2002 & Adapted Social Capital Assessment Tool-ASCAT \\
\hline 20 & Grootaert, Narayan, Jones, \&Woolcock, 2003 & Integrated Questionnaire for the Measurement of Social Capital - SC-IQ \\
\hline 21 & Narayan, \& Cassidy, 2001 & Social Capital Inventory \\
\hline 22 & $\begin{array}{l}\text { Webber \& Huxley 2007; } \text { Van } \\
\text { Gaag\&Snijders } 2005\end{array}$ & The Resource Generator \\
\hline 23 & $\begin{array}{l}\text { Van Der Gaag\& Webber 2008; Lin\& Fu. } \\
\text { 2001; Lin \&Dumin } 1986\end{array}$ & Position Generator \\
\hline 24 & McCallister\& Fischer 1978 & Name Generator \\
\hline
\end{tabular}

\section{Name Generator}

This instrument is the oldest tool for measuring individual social capital stem from 1970s researches on social network. It consists of general social network inventory accomplished with the blend of name generator and interpreter questions. Initially, it was aimed for the assessment of social network size and the recognition of its content and structure. In collecting data using this instrument, three sequences of data collection is being 
carried out. Firstly, an organized lists of questions requesting the respondents to enumerate names of individuals they know, Secondly, name interpreter, gather facts about members in one's personal network enumerated. Thirdly, though non-compulsory, the assessment of the connections among alters (Van der Gaag\& Webber, 2008).

This instrument was the best method of evaluating social capital till the mid-90s, it is still being used in social network structure studies as the blend of generator and interpreter can offer vary comprehensive facts about social capital and network. Although important, it was challenged for being costly, interviews can be very long and repetitive in study involving diverse network, it is difficult to interpret and compare the outcome of the studies (Van der Gaag\& Webber, 2008), time consuming (Verhaeghe, Van de Putte, \&Roose 2013) and it neglects other part of the social capital as it measures only some aspect of social capital (the number of alters), therefore no longer in use (Wang et al., 2014).

\section{Position Generator}

This instrument concentrates rather more on the existence of social resources then the connections within the network (Lin, Fu, \& Hsung, 2001). It is meant to consider the social capital in the holistic individuals' life. It usually ask from the list of ten to thirty different occupations whether respondents know and can identify anyone that engage in the listed type of occupation (Verhaeghe et al., 2013) and whether they are family members, colleagues and friends. The data gathered from this instrument are based on the notion that the occupation of the members in the network denote collections of social resources that can be measured quantitatively with job prestige measures. The fundamental assumptions of this instrument are that getting access to individuals with high prestige occupation provides access to enormous amount of resource and such peoples may apply crucial effect on their social network (Van der Gaag\& Webber, 2008).

For its 'easy to administer' feature, position generator has been regularly used since its development and has gain popularity especially when measuring social capital at individual level (Verhaeghe et al., 2013). Nevertheless, it suffer validity and reliability challenges (Verhaeghe et al., 2013; Van der Gaag, \& Webber, 2008). The listing method used to measure social capital is an approach, which is complicated for data collection, hard to produce measurement scores as it uses open-ended answers. Furthermore, there is absence of standard list of occupation to be included (Wang et al., 2014).

\section{Resource Generator}

One of the measurements of social capital that received great attention in the social capital literature is developed by Van der Gaag and Snijders (2005). Its reliability and validity across different cultural settings makes it transferable to diverse cultural context and therefore most applicable scale then other scales such as position generator and name generator (Häuberer, 2014, 2011; Webber, \& Huxley, 2007) which were both developed to measure individual social capital (Lin \& Erickson 2008; van der Gaag\&Snijders, 2005). It deals with resources in different facets of life that satiates the desires of individuals in the contemporary society (van der Gaag\&Snijders, 2005). Consequent to the notion that resources are the ingredients necessary for the achievement of economic and social mobility which differ from culture to culture, hence, the need for it to be considered and therefore the idea behind the construction of resource generator. The distinguishing factor between resource generation and other scales is the emphasis on particular critical resources for social capital generation in a particular settings (Foster \& Maas, 2014). The scale measures people access to social wealth inherent in their social network (Webber \& Huxley, 2007) as such, its items are directly asking about some particular resources available in the social network (Verhaeghe et al., 2013). It presents a novel way of measuring the construct using a checklist where by access is ticked against an arranged list of crucial and concrete resources (Van Der Gaag\& Webber, 2008).

Although, it is more robust and economical then the other generators, its findings are strictly restricted to the resource items used (Verhaeghe et al., 2013). Also, the scale suffers some methodological issues. For instance, some of its items lack validity, inserting items for actual resource in the scale is hard to attain with any academic and statistical rigor (Van Der Gaag\& Webber 2008). More so, there is high items popularity which is very easy for the respondents to check yes answer on question whether it is simple to access benefit from their network; this also shows vulnerability for socially desirable response (Van der Gaag\&Snijders, 2005).

\section{Social capital assessment tool (SCAT)}

SCAT was advanced by Krishna and Shrader (2000). It is a lengthy questionnaires (more than 60 questions) that was intended to assess social capital in developing nations (Harpham, Grant \& Thomas, 2002). It is established set of questions and approaches that evaluate the micro structural and cognitive levels of social capital in the communities that benefitted from development projects of the World Bank (Krishna \&Shrader, 2000). Although, the SCAT has robust operational significance (Krishna \&Shrader, 2000), some of the shortcomings of this scale is that it has not been subjected to statistical rigors (neither test of validity nor 
reliability). Also, some of its questions are overlapping, nonetheless, it offers important questions from which other measurement developers/users from different field of studies (e.g. Rastogi, Thapliyal, \& Hickey, 2014; Brune\&Bossert, 2009; Morgan, 2007) used (Agampodi et al., 2015).

\section{Adapted Social Capital Assessment Tool (A-SCAT)}

To remedy the problems inherent in the use of SCAT, A-SCAT was developed (Harpham et al., 2002). It is a concise scale that has two dimension of social capital, cognitive (eleven indicators) and structural (seven indicators) (Kim, Mancuso, Huang, \&Erkan, 2015). Like SCAT, A-SCAT is developed to be used in lowincome developing economies which is characterized by high level of illiteracy (Harpham et al., 2002). The scale has been validated and found to have content, face and construct validity, but reliability has not been ascertained (Verduin, Smid, Wind, \&Scholte, 2014). It has been validated and employed in Columbia (Harpham, Grant, \& Rodriguez, 2004), Peru, Vietnam, and Rwanda (Verduin et al., 2014), in Bangladesh (Story, Taleb, Ahasan, \& Ali, 2015) and in sub-Saharan Africa (Thomas, 2004). It has also been adapted by Young Lives (YL) in four less developed nations of Ethiopia, Vietnam, Peru and India (De Silva et al., 2006). For its good psychometric properties, several studies recommend it to be used especially in developing countries, (e.g. Agampodi et al., 2015).

The success of A-SCAT resulted in several adaption and modification which sees the emergence of other measurements such as Short version of adapted social capital assessment tool (SASCAT, SASCAT - B), personal social capital scale (PSCS) for health and behavioural science (Chen et al., 2009; Archuleta, \& Miller, 2011) and subsequently PSCS 16 and PSCS 8 (Wang et al., 2014).

\section{Personal Social Capital Scale (PCSC)}

Motivated by the outstanding performance of A-SCAT on the measurement of individual social capital, Chen et al., (2009) developed social capital scale - Personal Social Capital Scale (PSCS) to provide reliable instrument of individual social capital in health and behavioral science researches aimed at remedying the shortcomings inherent in the A-SCAT by plainly delineating what social capital is and what it does (Wang, Chen, Gong, \& Jacques-Tiura, 2014). This measure is based on the fact that social capital is part and parcel of individual's network connections that are characterized by reciprocity, trustworthiness and resource rich (De Silva, McKenzie, Harpham, \&Huttly, 2005; Harpham, 2002). It was first developed in Chinese version which contained Forty two items that measure ten statements (Cap1 - Cap10) with each five measuring bonding and bridging social capital respectively - thirty two items measuring bonding and ten measuring bridging, (Wang et al., 2014). Archuleta and Miller (2011) translated the Chinese version to English and tested its reliability and validity in two different countries including China and United States of America (USA). They found the instrument to be psychometrically fit (excellent validity and reliability) to measure individual social capital. The scale offers a valuable and practical instrument for health and behavioural researchers. It is capable of measuring the personally owned social capital, both its bridging and bonding aspect. It is also effective in acquiring required information from different respondents concerning their network connections. More importantly, it is simples and user friendly (Archuleta \& Miller, 2011).

\section{Personal Social Capital Scale 16 and 8}

The PCSC is challenged of being too large and content loaded and can be used for small sample survey. Therefore, there is the need to develop a scale that could be used for larger sample. Hence, (Wang et al., 2014) used PCSC item to develop two short versions, which they believe to be capable of catering for the larger sample survey. They termed them 'Personal Social Capital Scale 16 (PCSC 16)' consisting sixteen items, eight measuring bonding and bridging each, and 'Personal Social Capital Scale 8 (PCSC 8)' consisting eight items, four measuring bonding and bridging each. These two scales were tested for validity and reliability which they were found to have good psychometric properties (Cronbach's alpha of .90 and .83 respectively).

\section{Conclusion}

Although van Deth (2003) suggested that, evaluating the validity and reliability of social capital measures in different methods both longitudinally as well as cross-sectional should be a standard norm among social capital researchers and each facet of the construct should possess multiple indicators and rigorous statistical techniques for data reductions and normalization, unfortunately, this plea has not been heeded. For instance, De Silva et al. (2006) review of twenty-eight social capital empirical studies has exposed that only four has performed test of validity. He also found so many methodological flaws such as; measure not congruent to the definition, questions are not initially meant to measure social capital, questions do not measure intending social capital aspect, conglomerating aspects of social capital that are meant to be different into one score and absence of information on measurement validity. In line with Harpham, (2008), we suggest that there is the need for researchers to consider the current methodological strength of any given measurement from stream of literature before adapting or adopting.

\section{References}


[1]. Agampodi, T. C., Agampodi, S. B., Glozier, N., \&Siribaddana, S. (2015). Measurement of social capital in relation to health in Low and Middle Income Countries (LMIC); a systematic review. Social Science and Medicine. 128, 95-104.

[2]. Agénor, P. R., \&Dinh, H. T. (2015). Social capital, product imitation and growth with learning externalities. Journal of Development Economics, 114, 41-54.

[3]. Andrews, R., \& Brewer, G. A. (2015). Social Capital and Public Service Performance: Does Managerial Strategy Matter?. Public Performance and Management Review, 38(2), 187-213.

[4]. Andrikopoulos, A., \&Economou, L. (2015). Editorial board interlocks in financial economics. International Review of Financial Analysis, 37, 51-62.

[5]. Appel, L., Dadlani, P., Dwyer, M., Hampton, K., Kitzie, V., Matni, Z. A., ...\&Teodoro, R. (2014). Testing the validity of social capital measures in the study of information and communication technologies. Information, Communication and Society, 17(4), 398-416.

[6]. Archuleta, A. J., \& Miller, C. R. (2011). Validity Evidence for the Translated Version of the Personal Social Capital Scale among People of Mexican Descent. Journal of the Society for Social Work and Research, 2(2), 39-53.

[7]. Archuleta, A. J., \&Teasley, M. (2013). Acculturative stress among people of Mexican descent: The role of acculturation, social capital, and family role expectations. Social Work in Mental Health, 11(4), 311-333.

[8]. Barker, J., \& Thomson, L. (2015). Helpful Relationships with Service Users: Linking Social Capital. Australian Social Work, 68(1), $130-145$.

[9]. Bellamy, J. (2015). Volunteering Among Church Attendees in Australia. In Religion and Volunteering (pp. 121-143). Springer International Publishing.

[10]. Borges, C. M., Campos, A. C. V., Vargas, A. D., Ferreira, E. F., \&Kawachi, I. (2010). Social capital and self-rated health among adolescents in Brazil: an exploratory study. BMC research notes, 3(1), 338.

[11]. Brune, N. E., \&Bossert, T. (2009). Building social capital in post-conflict communities: Evidence from Nicaragua. Social Science and Medicine, 68(5), 885-893.

[12]. Carr, J. C., Cole, M. S., Ring, J. K., \&Blettner, D. P. (2011). A measure of variations in internal social capital among family firms. Entrepreneurship Theory and Practice, 35(6), 1207-1227.

[13]. Chen, X., Stanton, B., Gong, J., Fang, X., \& Li, X. (2009). Personal Social Capital Scale: an instrument for health and behavioral research. Health education research, 24(2), 306-317.

[14]. Chen, X., Wang, P., Wegner, R., Gong, J., Fang, X., \&Kaljee, L. (2015). Measuring social capital investment: Scale development and examination of links to social capital and perceived stress. Social indicators research, 120(3), 669-687.

[15]. Crossley, N. (2008). (Net) Working out: social capital in a private health club. The British journal of sociology, 59(3), 475-500.

[16]. De Silva, M. J., Harpham, T., Tuan, T., Bartolini, R., Penny, M. E., \&Huttly, S. R. (2006). Psychometric and cognitive validation of a social capital measurement tool in Peru and Vietnam. Social Science and Medicine, 62(4), 941-953.

[17]. De Silva, M. J., McKenzie, K., Harpham, T., \&Huttly, S. R. (2005). Social capital and mental illness: a systematic review. Journal of epidemiology and community health, 59(8), 619-627.

[18]. Dehkordi, L.F., Hossieni M.H., Naqipourfar V., \&Torkamani M. (2012). Studying the Role of Spiritual Leadership in Creating Social Capital in the Organization. Journal of Basic Applied Scientific Research, 2(8), 7566-7571

[19]. Durkheim E. Suicide: A Study in Sociology. Glencoe, IL: The Free Press, 1951.

[20]. Ellison, N. B., Gray, R., Lampe, C., \& Fiore, A. T. (2014). Social capital and resource requests on Facebook. new media and society, 16(7), 1104-1121.

[21]. Ferri, P. J., Deakins, D., \&Whittam, G. (2009). The measurement of social capital in the entrepreneurial context. Journal of Enterprising Communities: People and Places in the Global Economy, 3(2), 138-151.

[22]. Foster, K. A., \& Maas, C. D. (2014). An Exploratory Factor Analysis of the Resource Generator-United States: A Social Capital Measure. British Journal of Social Work, 46 (1), 8-26

[23]. Friche, A. A. D. L., Diez-Roux, A. V., César, C. C., Xavier, C. C., Proietti, F. A., \&Caiaffa, W. T. (2013). Assessing the psychometric and ecometric properties of neighborhood scales in developing countries: SaudeemBeaga Study, Belo Horizonte, Brazil, 2008-2009. Journal of Urban Health, 90(2), 246-261.

[24]. Grootaert, C., Narayan, D., Jones, V. N., \&Woolcock, M. (2003). Integrated questionnaire for the measurement of social capital. The World Bank Social Capital Thematic Group.

[25]. Hällsten, M., Edling, C., \&Rydgren, J. (2015). The effects of specific occupations in position generator measures of social capital. Social Networks, 40, 55-63.

[26]. Harpham, T. (2008). The measurement of community social capital through surveys. In Social capital and health (pp. 51-62). Springer New York.

[27]. Harpham, T., Grant, E., \& Rodriguez, C. (2004). Mental health and social capital in Cali, Colombia. Social science and medicine, 58(11), 2267-2277.

[28]. Harpham, T., Grant, E., \& Thomas, E. (2002). Measuring social capital within health surveys: key issues. Health policy and planning, 17(1), 106-111.

[29]. Häuberer, J. (2011). Social capital theory: Towards a methodological foundation. Springer Science and Business Media.

[30]. Häuberer, J. (2014). Social Capital in Voluntary Associations: Localizing Social Resources. European Societies, 16(4), $570-593$.

[31]. Inclan, C., Hijar, M., Tovar, V., 2005. Social capital in settings with a high concentration of road traffic injuries. The case of Cuernavaca, Mexico. Soc. Sci. Med. 61 (9), 2007-2017

[32]. Kiani, M. (2012). Women's Social Capital and Social Network in Iran.International Proceedings of Economics Development and Research, 42. 221-229

[33]. Kim, S. S., Mancuso, C. A., Huang, W. T., \&Erkan, D. (2015b). Social capital: a novel platform for understanding social determinants of health in systemic lupus erythematosus. Lupus, 24(2), 122-129.

[34]. Kobayashi, T., Kawachi, I., Iwase, T., Suzuki, E., \& Takao, S. (2013). Individual-level social capital and self-rated health in Japan: an application of the Resource Generator. Social Science and Medicine, 85, 32-37.

[35]. Krishna, A., \&Shrader, E. (2000). Cross-cultural measures of social capital: a tool and results from India and Panama. Social capital initiative working paper, 21 .

[36]. Lancee, B. (2015). Job search methods and immigrant earnings: A longitudinal analysis of the role of bridging social capital. Ethnicities, 1468796815581426.

[37]. Lee, S., Park, J. G., \& Lee, J. (2015). Explaining knowledge sharing with social capital theory in information systems development projects. Industrial Management and Data Systems, 115(5).

[38]. Liang, Q., Huang, Z., Lu, H., \& Wang, X. (2015). Social Capital, Member Participation, and Cooperative Performance: Evidence from China's Zhejiang.International Food and Agribusiness Management Review, 18(1), 49. 
[39]. Lin, N. \& Erickson, B.H. (2008) Theory, measurement, and the research enterprise on social capital. In Lin, N. \& Erickson, B.H., Eds., Social capital. An international research program. Oxford University Press Inc., New York. doi:10.1093/acprof:oso/9780199234387.003.0010

[40]. Lin, N., Fu, Y. C., \&Hsung, R. M. (2001). The position generator: Measurement techniques for investigations of social capital. In N. Lin, K. Cook, \& R. S. Burt (Eds.) Social capital: theory and research. New York: Aldine de Gruyter, 57-81.

[41]. Looman, W. S., \&Farrag, S. (2009). Psychometric properties and cross-cultural equivalence of the Arabic Social Capital Scale: instrument development study. International journal of nursing studies, 46(1), 45-54.

[42]. Mattoo, S. K., Bhansali, A. K., Gupta, N., Grover, S., \& Malhotra, R. (2008). Psychosocial morbidity in acromegaly: a study from India. Endocrine, 34(1-3), 17-22.

[43]. McCallister, L., \& Fischer, C. S. (1978). A procedure for surveying personal networks. Sociological Methods \& Research, 7(2), 131-148.

[44]. Modie-Moroka, T., 2009. Does level of social capital predict perceived health in a community?eA study of adult residents of lowincome areas of Francistown, Botswana. J. Health Popul. Nutr. 27 (4), 462-476

[45]. Morgan, A. (2007). 'You're nothing without me!': the positive role of education in regaining self-worth and 'moving on'for survivors of domestic abuse. Research in post-compulsory education, 12(2), 241-258.

[46]. Moscardino, U., Scrimin, S., Capello, F., \&Altoè, G. (2010). Social support, sense of community, collectivistic values, and depressive symptoms in adolescent survivors of the 2004 Beslan terrorist attack. Social Science \& Medicine, 70(1), 27-34.

[47]. Murayama, H., Nofuji, Y., Matsuo, E., Nishi, M., Taniguchi, Y., Fujiwara, Y., \&Shinkai, S. (2015). Are neighborhood bonding and bridging social capital protective against depressive mood in old age? A multilevel analysis in Japan.Social Science and Medicine, 124, 171-179

[48]. Murphy, L. (2013). The relationship between social capital and the director's duty to promote the success of the company. International Journal of Law and Management, 55(2), 86-102.

[49]. Muskett, J. A. (2014). Measuring religious social capital: Scale properties of the modified Williams Religious Social Capital Index among Friends of cathedrals. Journal of Beliefs \& Values, 35(2), 242-249.

[50]. Narayan, D., \& Cassidy, M. F. (2001). A dimensional approach to measuring social capital: development and validation of a social capital inventory. Current sociology, 49(2), 59-102.

[51]. Neves, B. B. (2013). Social capital and Internet use: the irrelevant, the bad, and the good. Sociology Compass, 7(8), 599-611.

[52]. Neves, B. B., \& Fonseca, J. R. (2015). Latent Class Models in action: Bridging social capital and Internet usage. Social science research, 50, 15-30.

[53]. Obikili, N. (2015). Social Capital and Human Capital in the Colonies: A Study of Cocoa Farmers in Western Nigeria. Economic History of Developing Regions, 30(1), 1-22.

[54]. Ooi, N., Laing, J., \&Mair, J. (2014). Social capital as a heuristic device to explore sociocultural sustainability: a case study of mountain resort tourism in the community of Steamboat Springs, Colorado, USA. Journal of Sustainable Tourism, (ahead-of-print), $1-20$.

[55]. Ou, Y. C., Hsu, L. C., \& Ou, S. L. (2015). Social Capital and Dynamic Capability Driving Competitive Advantage: The Moderating Role of Corporate Governance. International Business Research, 8(5), 1-18

[56]. Park, D. B., Nunkoo, R., \& Yoon, Y. S. (2015). Rural residents' attitudes to tourism and the moderating effects of social capital. Tourism Geographies, 17(1), 112-133.

[57]. Rastogi, A., Thapliyal, S., \& Hickey, G. M. (2014). Community action and tiger conservation: assessing the role of social capital. Society and Natural Resources, 27(12), 1271-1287.

[58]. Ritchie, M. B. K., \& Robison, M. L. J. (2012). Relationship economics: The social capital paradigm and its application to business, politics and other transactions. Gower Publishing, Ltd.

[59]. Roberts, J., \& Gannon, B. (2014). The multidimensional nature of social capital: an empirical investigation for older people in Europe. Sheffield Economic Research Paper Series (SERPS) 2014014.

[60]. Sabatini, F. (2009). Social capital as social networks: a new framework for measurement and an empirical analysis of its determinants and consequences. The Journal of Socio-Economics, 38(3), 429-442.

[61]. Story, W. T., Taleb, F., Ahasan, S. M., \& Ali, N. A. (2015). Validating the Measurement of Social Capital in Bangladesh A Cognitive Approach. Qualitative health research, 25(6), 806-819.

[62]. Story, W. T., Taleb, F., Ahasan, S. M., \& Ali, N. A. (2015). Validating the Measurement of Social Capital in Bangladesh A Cognitive Approach. Qualitative health research, 25(6), 806-819.

[63]. Strzelecka, M., \& Wicks, B. E. (2015). Community Participation and Empowerment in Rural Post-Communist Societies: Lessons from the Leader Approach in Pomerania, Poland. Tourism Planning and Development, (ahead-of-print), 1-17.

[64]. Thomas, E. P. S. C. (2004). Social capital and women's health in Sub-Saharan Africa (Doctoral dissertation, London South Bank University).

[65]. Thuy, N. T. M., \& Berry, H. L. (2013). Social capital and mental health among mothers in Vietnam who have children with disabilities. Global health action, 6.

[66]. Unni, A. S., (2014) A Study of Relationship between Social Capital and Organizational Citizenship Behavior. International Journal of Managerial Studies and Research (IJMSR) 2(4), 76-81

[67]. Van Der Gaag, M., \&Snijders, T. A. (2005). The Resource Generator: social capital quantification with concrete items. Social networks, 27(1), 1-29.

[68]. Van der Gaag, M., \& Webber, M. (2008). Measurement of individual social capital: questions, instruments, and measures. In: Kawachi, I., Subramanian, S.V., Kim, D. (Eds.), Social Capital and Health. Springer, New York, pp. 29-49.

[69]. Van Deth, J. W. (2003). Measuring social capital: orthodoxies and continuing controversies. International Journal of Social Research Methodology, 6(1), 79-92.

[70]. Van Staveren, I., \&Knorringa, P. (2007). Unpacking social capital in economic development: How social relations matter. Review of Social Economy, 65(1), 107-135.

[71]. Veerle, V., Wim, P., Jan De, M., \& Sara, W. (2012). Measuring the immeasurable? Operationalising social capital in health research. Health, 2012.

[72]. Verduin, F., Smid, G. E., Wind, T. R., \&Scholte, W. F. (2014). In search of links between social capital, mental health and sociotherapy: A longitudinal study in Rwanda. Social Science and Medicine, 121, 1-9.

[73]. Verhaeghe, P. P., Van de Putte, B., \&Roose, H. (2013). Reliability of Position Generator Measures across Different Occupational Lists A Parallel Test Experiment. Field Methods, 25(3), 238-261.

[74]. Villalonga-Olives, E., \&Kawachi, I. (2015a). The measurement of bridging social capital in population health research. Health \& place, 36, 47-56. 
[75]. Villalonga-Olives, E., \&Kawachi, I. (2015b). The measurement of social capital.Gaceta Sanitaria, 29(1), 62-64.

[76]. Wang, P., Chen, X., Gong, J., \& Jacques-Tiura, A. J. (2014). Reliability and validity of the personal social capital scale 16 and personal social capital scale 8: Two short instruments for survey studies. Social Indicators Research, 119(2), 1133-1148.

[77]. Webber, M. P., \& Huxley, P. J. (2007). Measuring access to social capital: The validity and reliability of the Resource GeneratorUK and its association with common mental disorder. Social Science and Medicine, 65(3), 481-492.

[78]. Williams, D. (2006). On and off the 'Net: Scales for social capital in an online era. Journal of Computer-Mediated Communication, 11(2), 593-628.

[79]. Woolcock, M. (2010). The rise and routinization of social capital, 1988-2008.Annual review of political science, 13, 469-487.

[80]. Zimet, G. D., Dahlem, N. W., Zimet, S. G., \& Farley, G. K. (1988). The multidimensional scale of perceived social support. Journal of personality assessment, 52(1), 30-41. 